\title{
Chapter 13 \\ Towards a Drought Policy in North-West European Regions?
}

\author{
Corinne Larrue, Nanny Bressers and Hans Bressers
}

\subsection{Introduction}

As presented in the previous chapters, to enhance the preparedness of NW European regions for periods of drought and water scarcity, the governance team used a governance assessment tool (GAT) to reveal the 'essence' of drought adaptation and governance in the six NW European regions investigated (see Chap. 3). We should remember that this governance assessment has been developed by social scientists with the help of practice partners (project partners from the region, such as water authorities and county councils) and other governmental and non-governmental stakeholders. This inclusion of practice partners has allowed a continuous iteration between science and practice, as well as access to regional stakeholders for interviews; in addition, it ensured an even representation of the relevant stakeholders. The contacts and networks of the practice partners facilitated the exchange with these regional stakeholders.

This 'Governance Assessment Tool' is composed of a 'matrix' style model that consists of five elements (levels and scales, actors and networks, perceptions of the problem and goal ambitions, strategies and instruments, and responsibilities and resources for implementation) and four criteria (extent, coherence, flexibility and intensity), producing a matrix of 20 cells. This model was used to diagnose the regional setting and to formulate regional roadmaps to optimize regional settings. As presented in the conclusion of the previous chapters, a qualitative evaluation has been performed for each region. For each case, the evaluation of the drought

\footnotetext{
C. Larrue $(\square)$

Paris School of Planning, University of Paris EST, Champs-sur-Marne, France

e-mail: corinne.larrue@u-pec.fr
}

H. Bressers

CSTM, University of Twente, Enschede, The Netherlands

N. Bressers

Water Authority Vechtstromen, Almelo, The Netherlands

(C) The Author(s) 2016

H. Bressers et al. (eds.), Governance for Drought Resilience,

DOI 10.1007/978-3-319-29671-5_13 
governance context has been summarized by assessing each of the 20 cells through a graphical visualization that shows the matrix with colours ('score cards'); these indicate the value of each cell (restrictive, neutral or supportive context).

Based on the conclusions of the cross-cutting perspective chapters and case study chapters, it is useful to propose a comparative approach of the drought governance context in the six regions studied. This comparison allows us to outline general trends that emerged from each of the cases and to show possible specificities of the regions studied. This comparison also allows us to analyse the specificity of each of the cross-cutting issues (i.e. nature, fresh water and agriculture) to note the contexts that facilitate or prevent a better drought governance context.

However, transferring the richness of the data gathered by numerous documents and interviews into more condensed layers of summary and ultimately into an overview has both positive and negative aspects. On the one hand, this transfer is necessary to enable a comparative analysis between several cases; however, on the other hand, the summary should not hide essential observations that provide evidence for the scores. Thus, one should always remember that such a summary of summaries is a derivative of a much richer set of observations and their interpretation. In addition, the matrices have been implemented independently by different leading authors. In order to overcome the fact that certain authors differ slightly in their 'judgments', several meetings with all the analysts have been held in order to reach a common agreement upon these assessments. Hence, for the comparison of the assessment of the different case studies, we used a greater amount of the written text for the assessments and did not only use the comparison of the matrices. However, to illustrate our comments in this text we based our comparative statements on the coloured matrix stemming from the regional case studies.

This chapter is devoted to concluding remarks. It will first present certain overarching observations related to case study results (Sect. 13.2) and to the three cross-cutting perspectives presented in the previous chapters (Sect. 13.3). In conclusion, we will then outline a few recommendations (Sect. 13.4).

\subsection{How Governance Can Be Characterized in Each Region?}

The outcomes of the analysis of the drought-related water governance issues in the NW European regions involved in the DROP project can be summarized by the three following main points:

- A low level of awareness exists, as regards the drought issue, creating a poor context for responsibilities and resources, and leading to a very low level of intensity of drought-related actions

- However, an effective water governance, particularly for networks of actors, and their involvement at different levels and scales exists in all regions

- Although variable according to the region, there is a low level of flexibility in the governance context 


\subsubsection{A Low Level of Awareness as Regards the Drought Issue}

The problem with perceptions and goal ambitions is that this is the dimension in which the governance context does not favour drought policy. The four criteria of this dimension are either neutral (yellow) or restrictive (red) in most of the studied regions, particularly where the intensity is concerned. This is shown in Table 13.1.

In fact, in most of the studied regions and primarily because of the traditionally wet situation of the NW regions, many actors involved in water governance are not aware of the potential drought situation or do not see it as a priority. These actors are much more preoccupied with floods. Additionally, in the Somerset case, in which the awareness of drought impacts was high at the beginning of the project, the flood event that occurred during the course of the DROP project changed the minds of those involved and allowed them to forget the drought issue for some period.

In nearly all cases, the intensity of problem perceptions as well as of goal ambitions is the worst dimension for the drought governance context. In several cases drought issues were introduced during the interviews with the governance team.

This low level of drought awareness results in a low-intensity assessment of all of the dimensions of the governance context (Table 13.2). If we consider the intensity criteria for all the dimensions in each region, we can assess that the intensity quality is either restrictive (red) or neutral (yellow) in all of the regions and

Table 13.1 Assessment of problem perceptions and goal ambitions criteria in the six regions

\begin{tabular}{|l|l|l|l|l|}
\hline & Extent & Coherence & Flexibility & Intensity \\
\hline SALLAND & & & & \\
\hline FLANDERS & & & & \\
\hline TWENTE & & & & \\
\hline SOMERSET & & & & \\
\hline VILAINE & & & & \\
\hline EIFEL RUR & & & & \\
\hline
\end{tabular}

Table 13.2 Intensity assessment for all of the dimensions in all of the regions

\begin{tabular}{|l|l|l|l|l|l|l|}
\hline \multicolumn{1}{|c|}{ Intensity } & Salland & Flanders & Twente & Somerset & Vilaine & Eifel Rur \\
\hline Levels and scales & & & & & \\
\hline Actors and networks & & & & & \\
\hline $\begin{array}{l}\text { Problem perspectives and } \\
\text { goal ambitions }\end{array}$ & & & & \\
\hline Strategies and instruments & & & & & \\
\hline $\begin{array}{l}\text { Responsibilities and } \\
\text { resources }\end{array}$ & & & & & \\
\hline
\end{tabular}


almost all of the dimensions. Taking into account the outcome of the regional case study analysis we can relate low level of drought awareness and low level of intensity of the drought governance context in NW regions.

Next to the dimension of problem perception and goal ambitions, also the dimension of responsibilities and resources for implementation is problematic. It generally scored low on coherence, flexibility and intensity, though not on extent.

In most of the regions studied, the drought issue is not completely out of sight. The actors interviewed are aware of the potential occurrence of such a drought situation. Therefore, in most cases, the governance team members positively assessed the extent of the responsibilities and resources or the strategies and instrument dimensions. However, this does not always imply a true involvement of the stakeholders, preventing them from developing a coherent policy in this area. The anticipation capacity throughout all of the regions is limited to a few measures, the relevance of which is easily challenged if other more urgent problems arise, as in the Somerset case.

\subsubsection{Effective Water Governance as Regards Actors and Their Networks in All of the Regions}

In contrast to the situation of awareness and intensity, we observed a much better drought governance context as regards the actors and networks dimension as well as the levels and scales dimension (see Table 13.3 for the actors and networks dimension). In all of the regions studied, the actors involved at different decision levels are mobilized, which constitutes a context that is particularly favourable to the establishment of a drought policy that integrates these different levels. Most of the qualities in the actor and network dimension have been assessed by the governance team members as supportive (green) or neutral (yellow), though even here intensity remains the weakest part.

These conclusions can be related to the existing water governance systems in most regions. In all countries, water governance is relatively effective because a water policy has already been implemented since the $60 \mathrm{~s}$. This aspect of being a

Table 13.3 Actors and networks criteria in all of the regions

\begin{tabular}{|l|l|l|l|l|}
\hline & Extent & Coherence & Flexibility & Intensity \\
\hline SALLAND & & & & \\
\hline FLANDERS & & & & \\
\hline TWENTE & & & & \\
\hline SOMERSET & & & & \\
\hline VILAINE & & & & \\
\hline EIFEL RUR & & & & \\
\hline
\end{tabular}


Table 13.4 Coherence assessment for all of the dimensions in all of the regions

\begin{tabular}{|l|l|l|l|l|l|l|}
\hline Coherence & Salland & Flanders & Twente & Somerset & Vilaine & Eifel Rur \\
\hline Levels and scales & & & & & & \\
\hline Actors and networks & & & & & & \\
\hline Problem perspectives and & & & & & & \\
\hline Strategies and & & & & & & \\
\hline $\begin{array}{l}\text { Responsibilities and } \\
\text { resources }\end{array}$ & & & & & \\
\hline
\end{tabular}

relatively established sector has been recently reinforced by the implementation of the Water Framework Directive (WFD), which imposes a multilevel water policy through the formulation of a district management plan.

More precisely, if we consider the coherence criteria for all the dimensions in each region, we can assess a supportive governance context as regards this quality. Most of the cells have been assessed supportive (green) or neutral (yellow). However, this is essentially true for both of the dimensions, 'levels and scales' and 'actors and networks'. When addressing issues that are more closely related to drought as regards responsibilities or strategies, the coherence appears to be much less evident in each of the regions studied (Table 13.4). This evaluation reflects the fact that the drought issue is not truly at stake for several water actors.

Moreover, it stems from the more detailed regional case study reports that where it exists, the governance consistency is mainly due to strong interrelationships between actors based on mutual trust.

More generally, water governance implemented within each of the regions produced interactive knowledge between actors: most of them met often and know well each other's perspectives and have developed a common knowledge around water issues. Even if their position can be conflictual, they share a mutual interest in water management, which can help the future formulation and implementation of drought policy.

\subsubsection{Although Variable According to the Region, There Is a Low Level of Flexibility of the Governance Context}

Considering the flexibility criteria for all the dimensions in each region, the analysis highlights a more neutral context (Table 13.5). Although different actors are mobilized at different decision-making levels, the system of interactions between the players apparently does not allow sufficient flexibility to enable the decision-making system to easily incorporate new issues, such as drought or water scarcity. The governance context is not truly prepared to address the water scarcity and drought issue and to integrate it as an important issue. 
Table 13.5 The flexibility assessment for all the dimension in each of the regions

\begin{tabular}{|l|l|l|l|l|l|l|}
\hline Flexibility & Salland & Flanders & Twente & Somerset & Vilaine & Eifel Rur \\
\hline Levels and scales & & & & & & \\
\hline Actors and networks & & & & & & \\
\hline $\begin{array}{l}\text { Problem perspectives and } \\
\text { goal ambitions }\end{array}$ & & & & & & \\
\hline Strategies and instruments & & & & & & \\
\hline $\begin{array}{l}\text { Responsibilities and } \\
\text { resources }\end{array}$ & & & & & & \\
\hline
\end{tabular}

However, the flexibility of governance may be more constrained by the institutional context of each country or region than by the level of consciousness. We can then observe that the Flanders case as well as the Eifel-Rur case appear to have the most neutral context as regards flexibility (all of the dimensions are assessed as neutral as pointed out in Table 13.5). This assessment can be related to the lack of flexibility in general which has been pointed out in the case study chapters about these two regions.

In sum, the implementation of the GAT leads to the conclusion that the governance context for drought resilience policies and measures in most of the regions studied can be regarded to currently be 'intermediate'. This tool does not conclude to a clear positive or negative picture of the drought and water scarcity governance context in those NW regions. The governance circumstances appear to be half capable of providing a favourable context in terms of the actors and decision levels involved in all of the regions, but do not provide a really favourable context to develop and implement a coherent drought policy.

\subsection{Outcome of the Analysis: A Cross-cutting Perspective}

Drought or water scarcity situations either during a short period or as a more structural pattern, leads to readdress the issue of allocation of water uses and the related water user rights. In NW European regions this water management issue is changing: from how to better allocate water between sectors towards how to minimize impacts from one user or stakeholder to another, trying to better combine uses. However, for the six regions studied this question is only partially at stake until now, due to the low level of drought awareness as pointed above.

Indeed while we can witness a beginning trend to view the negative water balance during dry summers as a problem that needs to be addressed, very little was done up to now to solve the problem in practice.

Stemming from the cross-cutting analysis presented above, three mains issues can be pointed out in order to characterize the way the sectors' needs are taken into account. 
- Water governance that in general gives more weight to representatives of economic interests than to environmental ones

- A hierarchy as regards water uses in case of water scarcity that favours drinking and service water supplies

- Contrasting initiatives which try to better take into account drought in all sectors

\subsubsection{Water Governance Gives More Weight to Representatives of Economic Interests Than to Environmental Ones}

Together with traditional water users (water supply, industries, etc.) the agricultural sector relies upon water rights that it holds from the past. It is thus hard to take these rights and to redistribute them among new sectors as nature-related ones.

More precisely, due to the relative importance of the agricultural sector in the regional economy of the studied regions, the agriculture production influences water governance. The governance of drought and water scarcity reserves an important listening ear towards representatives of agricultural sectors in all the regions. Moreover, this economic sector proved to be well organized and to operate with a high level of interactive capacities in all the regions.

One can notice that multilevel interactions are quite varied between the regions studied. In most cases, water authorities have taken the lead in drought resilience management, but the involvement of other stakeholders is not balanced: environmental NGOs find it difficult to make their voices heard, due to the focus on agriculture and economic development (tourism, urbanization, etc.).

However in some regions like the ones studied in the Netherlands, it is worth noting that agriculture is not always ranked at the highest priority level. In that country, part of surface water needs to be flushed to prevent salt intrusion in the low-lying western parts of the country, which implies a lower availability for agricultural use in the east part, and within the displacement chain, which outlines the priorities of competing water uses during dry periods, agricultural production has a low priority. This hierarchy between sectors must thus be analysed through the lenses of geographical and sociopolitical context.

It has been pointed out in the nature cross-cutting chapter that in each region, the water system has been modified in the past, either for purposes of flood protection or freshwater delivery or agricultural efficiency or all at the same time. All of these interventions had side effects on other services of the water system that were often not recognized when the interventions took place. These modifications question the level of 'naturality' to be taken into account which does not help to reallocate water rights to 'nature-related stakes'. 


\subsubsection{A Hierarchy as Regards Water Uses in Case of Water Scarcity that Favours Water Supplies}

The three cross-cutting chapters clearly show that the impact of drought on water supplies is generally taken into account than the two other issues: agriculture and nature. In all of the cases studied, the priority is given to human water uses when the resource becomes scarce, even if we witness a growing sensibility, which tends to question this hierarchy especially in the Netherlands. In all the regions, freshwater availability for drinking water provision is usually ranked as a priority stake.

Moreover, the regional analysis pointed out that disruption in freshwater delivery is considered as a management mistake. That explains the difficulty to question the hierarchy already settled in favour of freshwater supply.

Last, it is worth noting that the impact of drought is not only a quantitative issue. For freshwater supply it is mostly a qualitative one. As stated above, during drought episodes, water quality in lakes and reservoirs generally shows deterioration due to less dilution, particularly for nutrients and salinity which oblige to increase water treatment for drinking water production. This is why in some regions the main focus is given to be better prepared for crisis management.

\subsubsection{Contrasting Initiatives Which Try to Better Take into Account Drought in All Sectors}

While our first two observations are somewhat pessimistic that are also numerous initiatives that have been pointed out in the six regional case study chapters which cannot all be reported here. We can stress here the main trends along four main lines:

- Awareness: even if awareness proved to be low in each region, gradually the agricultural sector becomes more sensitive to drought risk as a result of past events. Moreover, it has been stressed in some cases that the fundamental nature of drinking water provision and freshwater availability may be the leading entryway to the development of drought risk awareness and drought adaptation measures.

- Knowledge: a better knowledge about agricultural and individual water uses is recognized in all the regions as a necessity, and new tools are implemented in order to strengthen this knowledge capacity. To that respect, the developed web platform (www.water.be) with the modelling results in Flanders can increase the awareness for the problem, if it is used as an information channel, e.g. by farmers. Increased communication of risk to actors which have underdeveloped risk perception is then recommended. For these activities the developed scientific model can be used, but the more technical approach should be combined 
with a more interactive approach, e.g. with showcases on local level together with farmers.

- Engineering: in most regions there is a need for additional buffering capacity by enlarging the infrastructure interconnectivity among catchments. Connectivity appears to be the key to addressing the crises. In some regions, water saving technics in agriculture and other sectors begin to be developed.

- Planning: there is a critical need for more integrated land and water management perspectives. The mobilization of new water resources, through the building of water retention basins, for instance must not be considered as a paramount unique solution and must be integrated within a comprehensive drought plan.

\subsection{Conclusions and Recommendations Stemming from the Implementation of the GAT}

In conclusion of this presentation of the governance assessment's main outcomes, we can generally state that the context of governance could be greatly improved by an awareness of the importance of drought conditions and a greater focus on its prevention.

Forty recommendations have been made to the regional practice partners by the governance team members. We will present some of our more general observations and recommendations, which partly stem from regional observations, but which have relevance and transferability to other regions in North-west Europe.

\subsubsection{Continuous Focus on Realizing Awareness Is Needed}

The main and first recommendation to be stressed is a focus on raising the awareness of drought and water scarcity in all of the NW regions.

Across the areas studied, we found that the problem was that the awareness among land owners and the general public, and thus many politicians, remains low. This lack of awareness restricts the selection of forceful interventions to increase drought resilience and occasionally makes it more difficult to practically realize the measures chosen.

Based on the governance team visits, the discussions with the water authorities and with many other stakeholders, and the results of the governance assessment, it was possible to achieve certain major recommendations regarding this central issue, which is the awareness and strengthening of drought and water scarcity issues' position on public and political agendas in the various countries. 
We can distinguish three major strategies for pushing the position of the drought issue that is still experienced by many as a second-order issue.

(1) Aiming to place drought and water scarcity on the public and political agendas on their own, as independent problems; for instance, by providing continuous information to the public, such as in Flanders, on the agency's website or by directly addressing national water planners with a broad coalition of stakeholders, such as in the Netherlands' Delta programme process.

(2) Addressing drought by 'piggybacking' other issues, i.e. including drought-relevant measures in different planning initiatives and ensuring the coherence of plans with drought objectives.

(3) Preparing a ready-to-implement strategy for when a drought event makes the topic climb the agenda and receive political attention, resulting in a call for action.

The careful application of a combination of these strategies leads to the best positioning of drought issues and aligns them more closely with the already recognized importance of flood risks.

More generally, the issue of drought can be related to the issue of climate change: better knowledge of the regional effects of climate change on water availability can be a first step to improving visibility and understanding of the problem, even if this might be obviously not true everywhere, that it will not be sufficient as such.

\subsubsection{Preparation and Implementation of Water Demand Management}

Most measures involve distributing the available water and decreasing water scarcity during dry periods to make the areas more resilient by improving their water buffering capacity. Until now, measures oriented towards water demand have been less common. However, in the future, they might need to become a more common part of the drought resilience strategy, even in several areas in water-rich North-west Europe. This implies a current need for the collection of data on water rights, the following of water uses, and a review of water prices. Policy measures and instruments should generate incentives for use reduction that are now often absent, as water is still regarded as a free commodity rather than as a scarce resource. Thus, fostering the mainstreaming of drought risk and drought preparedness into private actors' activities is important.

Collaboration with farmers proved to be very important in most cases in the DROP project, not only in the two cases in which the pilot project was explicitly addressing agriculture. Increasing synergies with agriculture, e.g. through farmer advisory services or the inclusion of farmers unions in the design and implementation of measures, seems to be a prerequisite for successful demand management. 
The management of expectations might be equally important. As long as the abundance of water in North-west Europe is taken for granted by water users, the implicit responsibility to protect the water supply is placed by the users on the water authorities. Although water supply should remain a public task, it does not follow that the water authorities and taxpayers' money should accommodate increased vulnerability for shortages or new economic activity requiring extra fresh water or water of a specific quality. Some investments might not be wise in areas prone to drought. Openly discussing the limits of public responsibility might increase the awareness and ownership of preparatory measures of such water users.

\subsubsection{The Need for an Increased Integration of Flood and Drought Management}

In our project, the UK Somerset case is a clear example of a situation in which, after several years of droughts, the large 2013-2014 flood disturbed the balance between drought and flood measures and proved that both are sides of the same climate change adaptation coin. It is essential to consider surplus water events when taking drought resilience measures, and vice versa. Recognizing the need to address the impact of floods, while acknowledging that there is also a very real threat of water scarcity in North-west Europe, changes the range of strategies and instruments that could be used to effectively mitigate variability and extremes. This more closely aligned approach of different forms of water management draws together a range of lessons for more the effective governance of climate change adaptation across the whole of North-west Europe. We need strategic governance approaches that are focused on adaptation and resilience of the entire water system rather than on crisis management of extreme events.

\subsubsection{Variety Requires Tailored Action}

Each of our six regional reports contains specific background information, analyses of governance conditions, and some recommendations on how to deal with the regional water governance situation from a drought perspective. The recommendations are partially based on a comparison of the specific region's context with the Governance Assessment Team members' knowledge of other water management systems, including a comparative analysis of the other five regions studied in DROP.

In the six regions studied, there are wide varieties of drought measures implemented-involving inter alia and drought prediction models as well as building infrastructure for improved water level management, natural water retention measures, and farmer-targeted assistance to improve irrigation practices. This variety 
reflects the need for tailored action due to the variety of natural situations in the different regions of North-west Europe. While increased insight and data processing are needed to better understand the dynamics of the water system in regard to drought issues, the best measures are highly dependent on the geohydrological situation and structure of water demand. However, the governance context also has a clear influence on the development of habitual approaches in policy-making and implementation. Some of the variety is not so much the result of physical conditions, but more so of governance settings.

These four main recommendations, drawn from the case studies and cross-cutting studies, may help regional actors to formulate and implement means able to address regional drought adaptation.

Open Access This chapter is distributed under the terms of the Creative Commons Attribution-NonCommercial 2.5 License (http://creativecommons.org/licenses/by-nc/2.5/), which permits any noncommercial use, duplication, adaptation, distribution, and reproduction in any medium or format, as long as you give appropriate credit to the original author(s) and the source, a link is provided to the Creative Commons license, and any changes made are indicated.

The images or other third party material in this chapter are included in the work's Creative Commons license, unless indicated otherwise in the credit line; if such material is not included in the work's Creative Commons license and the respective action is not permitted by statutory regulation, users will need to obtain permission from the license holder to duplicate, adapt, or reproduce the material. 